\title{
Managing psychotropic drugs with efavirenz
}

\author{
Rachel Therrien BPharm MSc
}

\section{$\mathrm{R}$ Therrien. Managing psychotropic drugs with efavirenz. Can J Infect Dis Med Microbiol 2006;17(Suppl D):15D-16D.}

Efavirenz is in the non-nucleoside reverse transcriptase inhibitor category of HIV antiretroviral medicines. It is an in vivo inducer of the CYP3A4 isoenzyme within the cytochrome P450 (CYP450) system, and an in vitro inhibitor of the system's CYP2C9/2C19, 3A4 and 2B6 isoenzymes; as a result, concentrations of psychotropic drugs can be increased or decreased depending on the specific enzyme pathway involved in their metabolism. CYP3A4 is responsible for metabolizing many benzodiazepines and other psychotropics, as well as selective serotonin reuptake inhibitors and tricyclic antidepressants. As an inducer of CYP3A4, efavirenz can increase the rate at which these agents are metabolized, resulting in administered psychotropic drug levels that are below their therapeutic thresholds. Conversely, efavirenz is an inhibitor of CYP2B6, which metabolizes agents such as bupropion; consequently, bupropion levels in the blood can increase. Given the existing conflicting data, the clinician may find it impractical to use an evidence-based approach when concomitantly prescribing efavirenz and psychotropic drugs to their HIV patients. Instead, it may be preferable to use a more pragmatic approach that applies knowledge of the most current pharmacological and pharmacokinetic data for psychotropics and non-nucleoside reverse transcriptase inhibitors, which may help better predict their potential interactions.

Key Words: Antiretrovirals; CYP450; Drug interactions; Efavirenz; Inducer; Inhibitor; Psychotropic drugs; Side effects

C favirenz (Sustiva, Bristol-Myers Squibb Canada) is in the

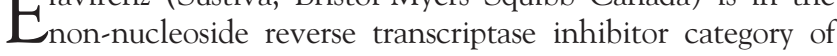
HIV antiretroviral medicines. It is an in vivo inducer of the CYP3A4 isoenzyme within the cytochrome P450 (CYP450) system, and an in vitro inhibitor of the system's CYP2C9/2C19, $3 \mathrm{~A} 4$ and 2B6 isoenzymes $(1,2)$. As a result, concentrations of psychotropic drugs can be increased or decreased depending on

\section{Les psychotropes et l'éfavirenz}

L'éfavirenz est un médicament antirétroviral, utilisé dans le traitement des infections à VIH, qui appartient à la catégorie des inhibiteurs non nucléosidiques de la transcriptase inverse. Il s'agit d'un inducteur in vivo de l'isoenzyme CYP3A4 présente dans le cytochrome P450 (CYP450) et d'un inhibiteur in vitro des isoenzymes CYP2C9/2C19, 3A4 et 2B6; ainsi, la concentration sanguine de médicaments psychotropes peut augmenter ou diminuer suivant la voie enzymatique empruntée pour leur métabolisme. La CYP3A4 intervient dans le métabolisme de nombreuses benzodiazépines et d'autres psychotropes ainsi que dans celui des inhibiteurs sélectifs du recaptage de la sérotonine et des antidépresseurs tricycliques. Comme l'éfavirenz est un inducteur de la CYP3A4, il peut accroître la vitesse à laquelle ces médicaments sont métabolisés, d'où l'atteinte de concentrations sous-thérapeutiques de psychotropes. À l'inverse, comme l'éfavirenz est un inhibiteur de la CYP2B6, qui métabolise des substances comme le bupropion, il peut entrainer une augmentation de la concentration sanguine de ce dernier médicament. Étant donné l'existence de données divergentes sur le sujet, les cliniciens peuvent trouver difficilement applicable l'approche fondée sur des preuves chez les patients porteurs du VIH, qui doivent à la fois prendre de l'éfavirenz et des psychotropes. Dans ce cas, il peut être préférable de recourir à une approche plus pragmatique, qui s'appuie sur les données les plus récentes sur les propriétés pharmacologiques et pharmacocinétiques des psychotropes et des inhibiteurs non nucléosidiques de la transcriptase inverse, qui permettent de prévoir plus facilement les interactions éventuelles.

\section{TABLE 1}

Potential drug interactions with efavirenz

\begin{tabular}{|c|c|}
\hline Drug class & Notes \\
\hline \multicolumn{2}{|l|}{ Benzodiazepines and hypnotics or anxiolytics metabolized by CYP3A4 } \\
\hline 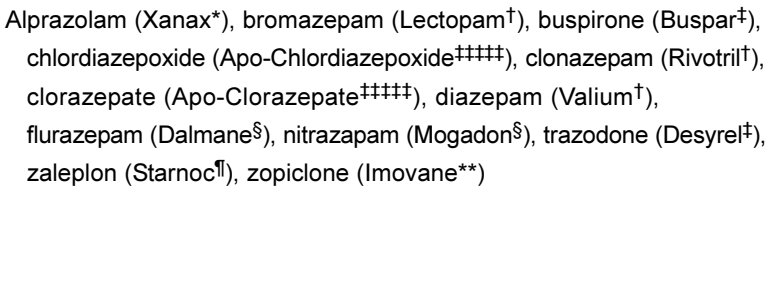 & 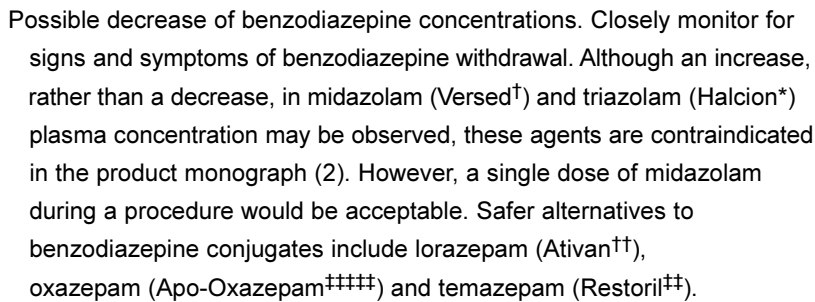 \\
\hline
\end{tabular}

continued on next page

Unités hospitalières de recherche, d'enseignement et de soins sur le sida (UHRESS)/Centre hospitalier de l'Université de Montréal (CHUM), Hôtel-Dieu, Montreal, Quebec

Correspondence: Ms Rachel Therrien, UHRESS-CHUM, 3840 rue St-Urbain, Montreal, Quebec H2W 1T8. Telephone 514-890-8148, fax 514-412-7234, e-mail rachel.therrien.chum@ssss.gouv.qc.ca 
TABLE 1 (CONTINUED)

Potential drug-drug interactions

\begin{tabular}{|c|c|}
\hline Drug class & Notes \\
\hline \multicolumn{2}{|l|}{ Antidepressants metabolized by CYP3A4 } \\
\hline 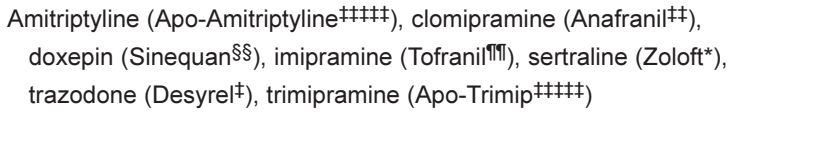 & $\begin{array}{l}\text { Adjust according to patient response and to the onset of adverse effects. A } 39 \% \\
\text { decrease in sertraline (Zoloft }{ }^{*} \text { ) concentration was observed (4). Possible decrease } \\
\text { in the concentration of antidepressants metabolized by CYP3A4. Monitor } \\
\text { the clinical efficacy of these agents. A dosage adjustment may be necessary. }\end{array}$ \\
\hline $\begin{array}{l}\text { Citalopram }\left(\text { Celexa }{ }^{* \star *}\right) \text {, escitalopram }(\text { Cipralex } \\
\text { venlafaxine }(\text { Effexort }) \text {, mirtazapine }\left(\text { Remeron }{ }^{\dagger+\dagger}\right) \text {, }\end{array}$ & $\begin{array}{l}\text { Also metabolized by CYP3A4, but due to their multiple metabolic pathways, } \\
\text { are subject to fewer drug interactions. }\end{array}$ \\
\hline Bupropion (Wellbutrin ${ }^{\ddagger \ddagger \ddagger}$, Zyban ${ }^{\ddagger \ddagger}$ ) & $\begin{array}{l}\text { Possible increase in bupropion concentration. Monitor for signs and symptoms of } \\
\text { bupropion toxicity (2). One case series (10 patients) examined in vivo experience } \\
\text { with the combination of bupropion and ritonavir, efavirenz or nelfinavir, and } \\
\text { found no increase in the number of seizures (no seizures were reported) (5). }\end{array}$ \\
\hline
\end{tabular}

Antidepressants that are CYP3A4 inducers

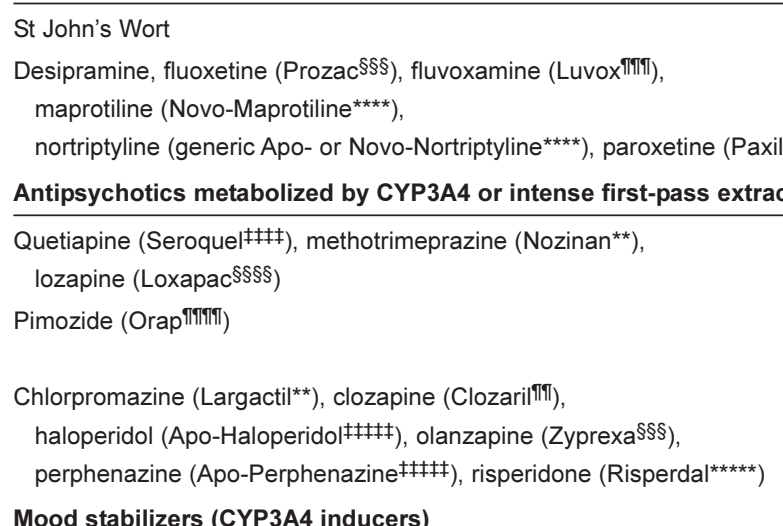

Possible decrease in efavirenz concentration. Contraindicated with efavirenz (Sustiva ${ }^{\ddagger}$ ). No anticipated effects.

Carbamazepine (Tegreto| |ศT), oxcarbazepine (Trilepta| $\mid$ Tा)

Possible decrease of efavirenz and decrease of carbamazepine concentration In one study, co-administration of efavirenz with carbamazepine led to a decrease in the area under the curve of efavirenz by $36 \%$ and a decrease in the area under the curve of carbamazepine by $27 \%$ (6). Avoid if possible, or closely monitor the efficacy of efavirenz. An efavirenz plasma concentration measurement may be indicated.

Valproic acid, lamotrigine (Lamictal ${ }^{\dagger+\dagger \dagger}$ ), lithium (Carbolith§) No anticipated effects.

Psychostimulants

Methylphenidate (Ritalin TाT), modafinil (Alertec ${ }^{\dagger+\dagger \dagger}$ )

Potentially metabolized by CYP3A4. Possible decrease in the concentration of methylphenidate and modafinil. Monitor clinical efficacy. A dosage adjustment may be necessary.

*Pfizer Canada Inc; †Hoffmann-La Roche Ltd; ${ }^{\star}$ Bristol-Myers Squibb Canada; §Valeant Canada Ltd; TServier Canada Inc; **Sanofi-Aventis Canada Inc; ${ }^{*}$ tWyeth Canada;

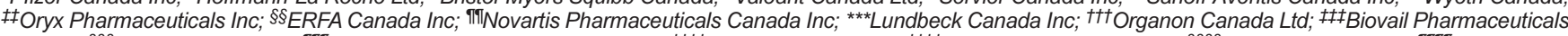

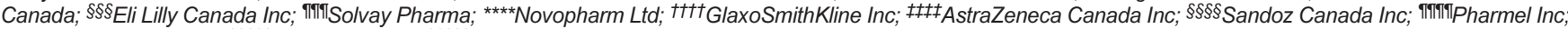

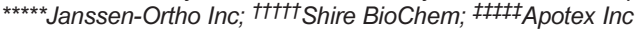

\section{CONCLUSION}

The concomitant use of psychotropic drugs and an efavirenz therapy regimen requires close patient monitoring to quickly identify drug interactions and ensure clinical efficacy. However, having a thorough knowledge of the various drugs' pharmacokinetics may help the clinician predict which interactions can potentially occur and select therapeutic agents accordingly. Often a dosage adjustment may be all that is necessary to resolve an interaction issue. It is also important that clinicians refer to the most up-to-date pharmacokinetic information available when prescribing these agents because changes tend to occur rapidly in this area.

\section{REFERENCES}

1. Sustiva Product Monograph. Mississauga: DuPont Pharma Inc, 2001.

2. Hesse LM, von Moltke LL, Shader RI, Greenblatt DJ. Ritonavir, efavirenz, and nelfinavir inhibit CYP2B6 activity in vitro: Potential drug interactions with bupropion. Drug Metab Dispos 2001;29:100-2.

3. Thompson A, Silverman B, Dzeng L, Treisman G. Psychotropic medications and HIV. Clin Infect Dis 2006:42:1305-10.

4. Ruiz NM, Labriola DF, Fiske WD, et al. Efavirenz plasma levels are unaffected in patients receiving selective serotonin reuptake inhibitors. 40th Interscience Conference on Antimicrobial Agents and Chemotherapy. Toronto, September 17 to 20,2000 . (Abst 1635)

5. Park-Wyllie LY, Antoniou T. Concurrent use of bupropion with CYP2B6 inhibitors, nelfinavir, ritonavir and efavirenz: A case series. AIDS 2003;17:638-40.

6. Kaul S, Ji P, Xie J, et al. A 2-way pharmacokinetic interaction between efavirenz and carbamazepine. 13th Conference on Retroviruses and Opportunistic Infections. Denver, February 5 to 8, 2006. (Abst 575a) 


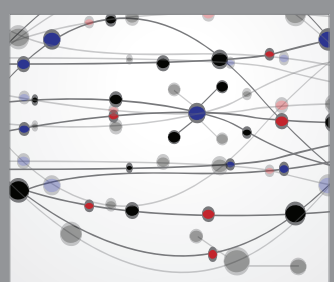

The Scientific World Journal
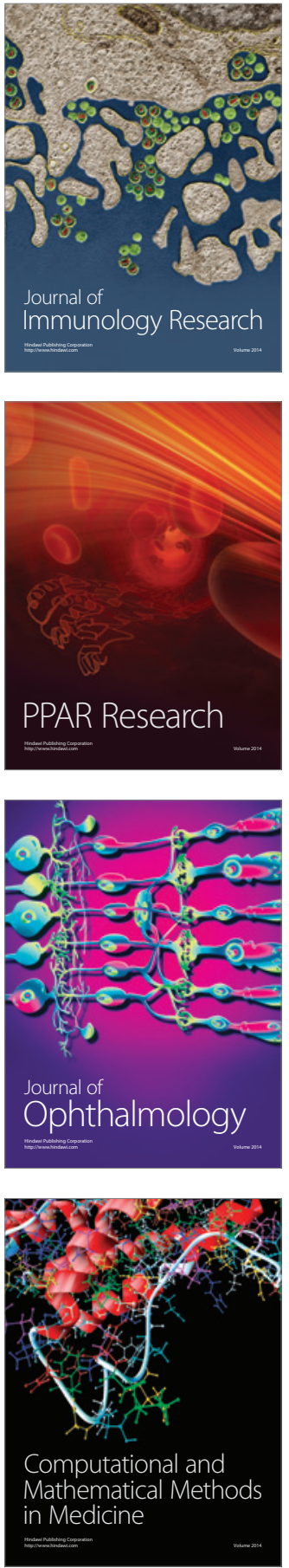

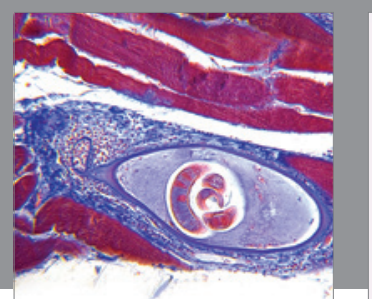

Gastroenterology Research and Practice

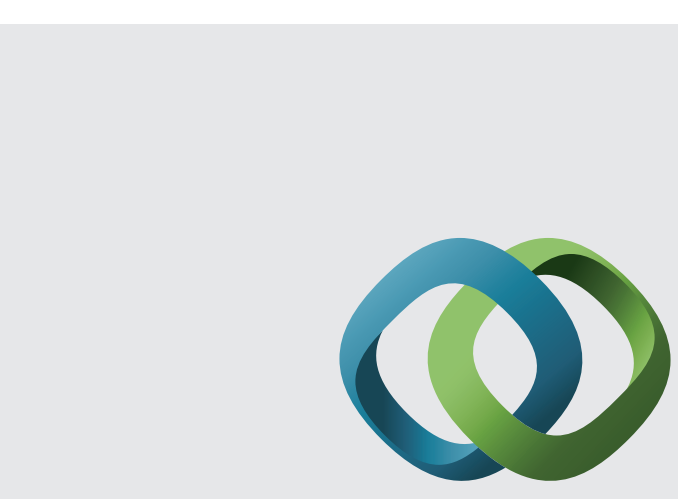

\section{Hindawi}

Submit your manuscripts at

http://www.hindawi.com
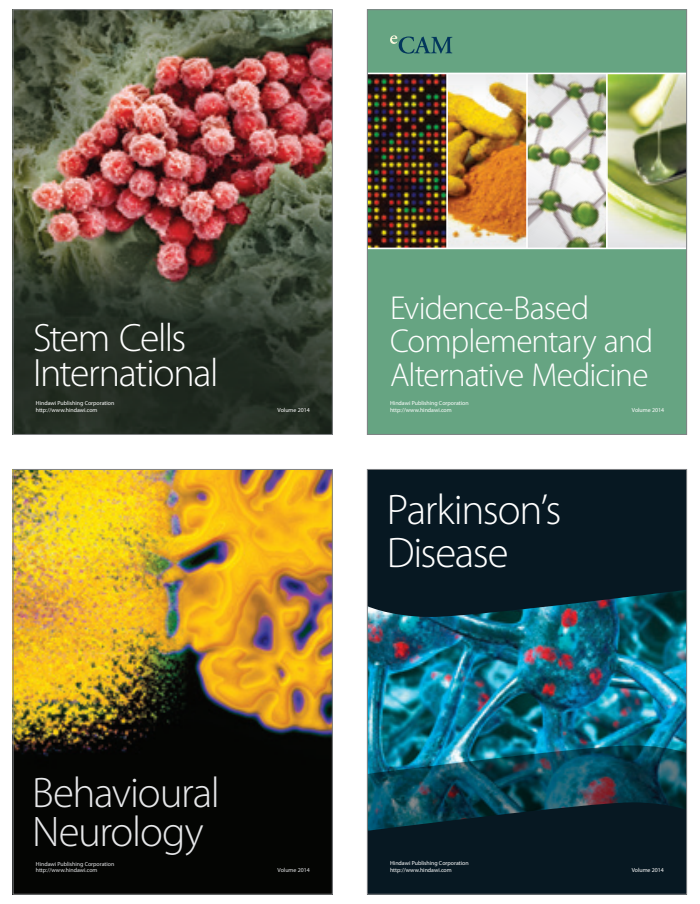
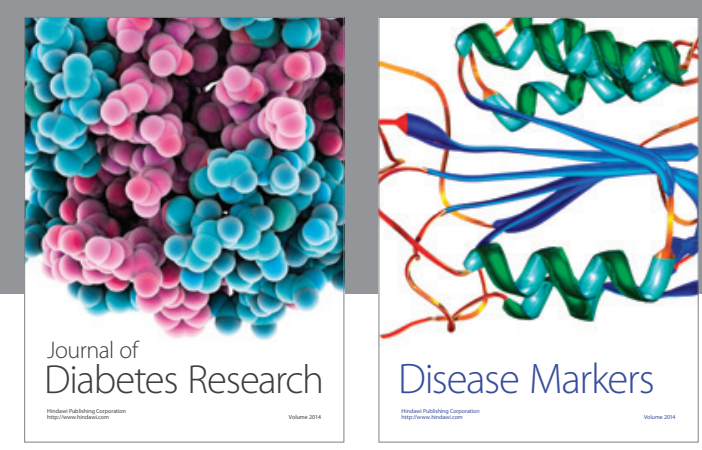

Disease Markers
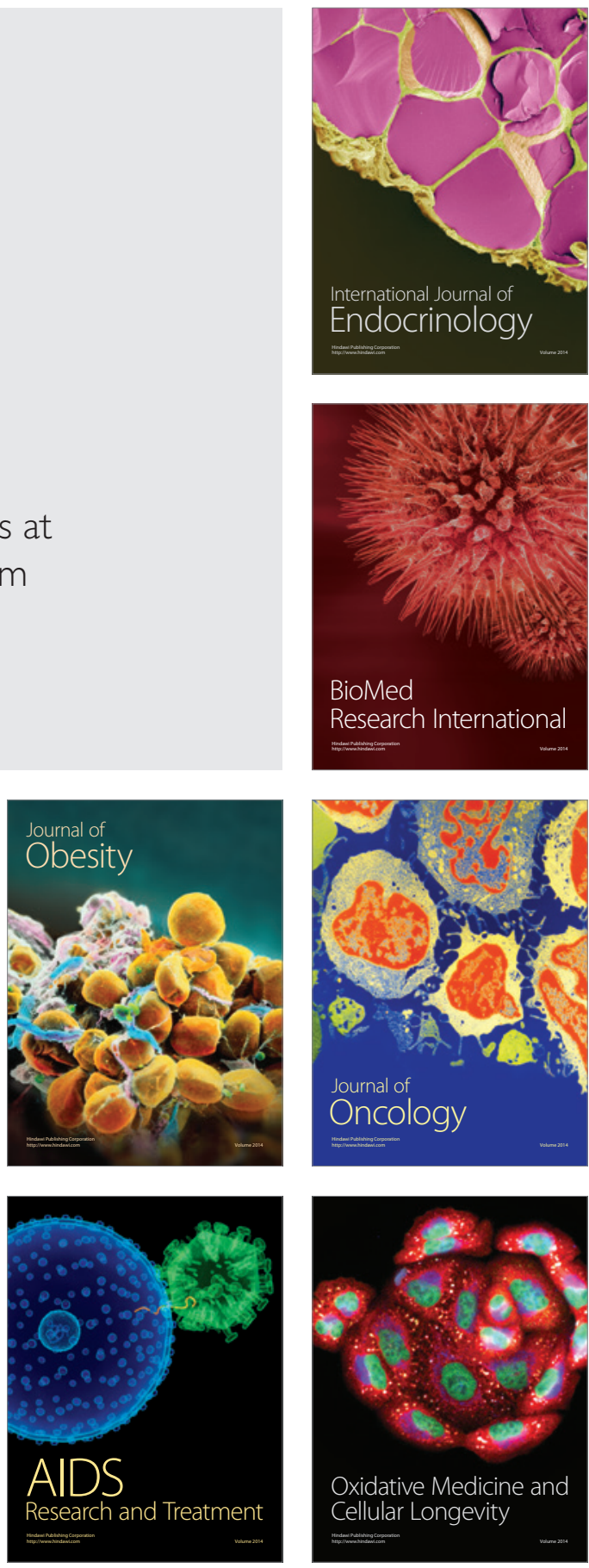